\title{
List of Maps
}

Map 1 Distribution of sample languages -19

Map 2

Map 3

Distribution of Pattern V against all other patterns in Africa $-\mathbf{2 6 3}$

Map 4

Distribution of patterns in Uto-Aztecan languages - 270

Map 5

Distribution of patterns in the Americas - 271

Map 6

Distribution of patterns in Asia -277

Distribution of patterns in Europe - 282

Map 7

Distribution of Patterns in Oceania - 288

Map 8

Global distribution of all patterns $-\mathbf{2 9 2}$

Map 9

Global distribution of Pattern $V(P=G=S)-294$

Map 10

Conflated global distribution of Pattern V $(\mathrm{P}=\mathrm{G}=\mathrm{S})$ in our and Stolz et al.'s (2017) sample languages -295 
